\title{
Profile and Prevalence of Dyslipidemia in Workplace in Togo
}

\author{
Wasungu Bassokla Ditorguéna ${ }^{1,}$, , Bana-ewai Essozimna Guy², Agbobli Yawo Apélété3, \\ Dadjo Soukouna Francis ${ }^{4}$, Atta Borgatia ${ }^{5}$, Pessinaba Souleymane ${ }^{6}$, Amevor Kodjo ${ }^{2}$, \\ Wognin Sangah ${ }^{7}$, Bonny Jean-Sylvain ${ }^{7}$ \\ ${ }^{1}$ Occupational Health Office, Ornamental's Stones and Marble Enterprise, Lome, Togo \\ ${ }^{2}$ Occupational Health Office, Togo's Telecommunication Enterprise, Lomé, Togo \\ ${ }^{3}$ Department of Medicine and Specialties, University of Lomé, Lomé, Togo \\ ${ }^{4}$ Labor and Social Laws Department, Lomé, Togo \\ ${ }^{5}$ Cardiology Office, CHU Sylvanus Olympio, Lomé, Togo \\ ${ }^{6}$ Cardiology Office, CHU Campus, Lomé, Togo \\ ${ }^{7}$ UFR Medical Sciences, University of Félix Houphouët Boigny, Abidjan, Côte d'Ivoire
}

Email address:

jpwasungu@gmail.com (W. B. Ditorguéna)

${ }^{*}$ Corresponding author

\section{To cite this article:}

Wasungu Bassokla Ditorguéna, Bana-ewai Essozimna Guy, Agbobli Yawo Apélété, Dadjo Soukouna Francis, Atta Borgatia, Pessinaba Souleymane, Amevor Kodjo, Wognin Sangah, Bonny Jean-Sylvain. Profile and Prevalence of Dyslipidemia in Workplace in Togo. Journal of Health and Environmental Research. Vol. 5, No. 2, 2019, pp. 50-53. doi: 10.11648/j.jher.20190502.13

Received: April 5, 2019; Accepted: June 2, 2019; Published: June 20, 2019

\begin{abstract}
Objectives: Dyslipidemia constitute a public health problem in the world. Very few studies were carried out on this subject in workplace. This work completed in workplace aimed to determine the prevalence of the dyslipidemia in workplace, to describe dyslipidemic profile in workers and its associated factors. Materials and Methods: It was about a descriptive cross-sectional study led June to September 2017 (04 months) on the medical files of the workers of a company of telephony in Togo. Were included the medical files comprising all the parameters of the lipidic assessment (total cholesterol, of triglycerides, the LDL and HDL cholesterol). The incomplete files were excluded. The dyslipidemia was defined for a total cholesterol higher than or $2,4 \mathrm{~g} / \mathrm{L}(6,2 \mathrm{mmol} / \mathrm{L})$ and/or a rate of HDL cholesterol lower than $0,4 \mathrm{~g} / \mathrm{L}(1$ $\mathrm{mmol} / \mathrm{L})$ at the man or lower than $0,50 \mathrm{~g} / \mathrm{L}(1,3 \mathrm{mmol} / \mathrm{L})$ at the woman and/or a triglyceride higher than $2 \mathrm{~g} / \mathrm{L}(2,3$ $\mathrm{mmol} / \mathrm{L}$ ) and/or a rate of LDLc $>1,88 \mathrm{~g} / \mathrm{L}$. Results: The average age of the workers was 46, 57 years $\pm 7,7$ (extreme of 28 and 60 years). The administrative staff was prevalent in a proportion of 53, 4\%. The pure hypercholesterolemia were most frequent (64\%), followed by hypo HDL cholesterol and mixed dyslipidemia respectively 16,4\% and 12,9\%. The dyslipidemia was isolated in $72 \%$ from the cases, was combined with another factor of cardiovascular risk such as arterial hypertension $(20,2 \%)$, diabete $(7,1 \%)$ and an ischaemic cardiopathy $(1,1 \%)$ of the cases. Conclusion: Dyslipidemias are a reality in occupational environment in Togo with high prevalence estimated at $60.3 \%$ and are associated to other factor of cardiovascular risk such as arterial hypertension, diabete, and overweight. So it seems necessary to lead occupational health programs in order to control them.
\end{abstract}

Keywords: Dyslipidemia, Prevalence, Workplace, Prevention

\section{Introduction}

In recent decades, African countries, including Togo, have been undergoing an epidemiological transition marked by the emergence of cardiovascular diseases for which the socioeconomic consequences are important [1-5]. At the origin of this pandemic, the major risk factors such as high blood pressure, diabetes, sedentary lifestyle, obesity and 
dyslipidemias, the prevalence of which continues to increase [5]. Indeed, the dyslipidemias are today a real public health problem [6, 8]. Formerly unknown in traditional African societies, the dyslipidemias have a considerable extent with prevalence differences of around $20 \%$ in the Maghreb countries $[9,10]$. In sub-Saharan Africa, high prevalence of more than $35 \%$ are reported in some areas [11-15]. Due to an often insidious development, the dyslipidemias often go unnoticed and sometimes discovered by chance during a routine consultation or in the search for factors associated with a cardiovascular pathology or its complications [16, 17]. Faced with this threat, the screening of cardiovascular risk factors and the implementation of prevention programs become necessary. In this sense, in the workplace during medical visits instituted as part of the surveillance of workers' health, the screening for the dyslipidemias through biochemical explorations in addition to the clinical investigations is useful [18-19]. However, despite their easy realization, very little data are available on the prevalence of the dyslipidemias in the workplace [20, 21]. It is in this context that this research work was initiated to contribute to the development of a prevention plan for the cardiovascular diseases in the workplace. The objective of our study was to determine the prevalence of the dyslipidemias in the workplace, describe the dyslipidemic profile of workers, and describe the factors associated with the dyslipidemia.

\section{Materials and Methods}

It was a descriptive cross-sectional study conducted from June to September 2017 (04 months) on the medical records of the workers of a telephone company in Togo. These files resulting from the annual medical examination of the staff were archived at the autonomous medical service of the company under the responsibility of the occupational doctor. The medical records including all lipid parameters (the total cholesterol, the triglycerides, the LDL and HDL cholesterol) were included. Incomplete files have been excluded. The dyslipidemia has been defined for the total cholesterolemia greater than or $2.4 \mathrm{~g} / \mathrm{L}(6.2 \mathrm{mmol} / \mathrm{L})$ and / or HDL cholesterol level below $0.4 \mathrm{~g} / \mathrm{L}(1 \mathrm{mmol} / \mathrm{L})$ in the adult male or less than $0.50 \mathrm{~g} / \mathrm{L}(1.3 \mathrm{mmol} / \mathrm{L})$ in adult female and / or a higher triglyceridemia than $2 \mathrm{~g} / \mathrm{L}(2.3 \mathrm{mmol} / \mathrm{L})$ and / or LDLc $>1,88 \mathrm{~g} / \mathrm{L}$. In addition, the subjects treated for a dyslipidemia by drug treatments were also counted. The dyslipidemic profiles were classified according to the criteria of Ferrieres J [22]: Pure hypercholesterolemia (total cholesterolemia greater than $6.2 \mathrm{mmol} / \mathrm{L}$ or $2.4 \mathrm{~g} / \mathrm{L}$ and triglyceridemia less than $2.3 \mathrm{mmol} / \mathrm{L}$ or $2 \mathrm{~g} / \mathrm{L}$ ); Low HDL cholesterolemia level (HDL less than $1 \mathrm{mmol} / \mathrm{L}$ or $0.4 \mathrm{~g} / \mathrm{L}$ in the male or less than $1.3 \mathrm{mmol} / 1$ or $0.50 \mathrm{~g} / 1$ in the female); Mixed hyperlipidemia (total cholesterolemia greater than $6.2 \mathrm{mmol} / 1$ or $2.4 \mathrm{~g} / 1$ and triglyceridemia greater than $2.3 \mathrm{mmol} / \mathrm{l}$ or $2 \mathrm{~g} \mathrm{/} \mathrm{1);} \mathrm{Hypertriglyceridemia} \mathrm{(total}$ cholesterolemia less than $6.2 \mathrm{mmol} / \mathrm{L}$ or $2.4 \mathrm{~g} / \mathrm{L}$ and triglyceridemia greater than $2.3 \mathrm{mmol} / 1$ or $2 \mathrm{~g} / \mathrm{l}$ ). The tables and figures were made using Microsoft Excel software.
The Chi-square test was used to compare the percentages with a significance level of $5 \%$.

\section{Results}

\subsection{Socioprofessional Characteristics of the Population}

Our study involved 746 medical records of workers representing 587 men (78.7\%) and 159 women (21.3\%) with a sex ratio of 3.7. The average age of workers was $46.57 \pm$ 7.7 years (range 28 to 60 years). The administrative staff was predominant at $53.4 \%$ (Table 1 ).

Table 1. Socioprofessional characteristics of the population studied.

\begin{tabular}{lll}
\hline & $\mathbf{N}$ & $\mathbf{\%}$ \\
\hline Age & & \\
$<30$ & 4 & 0.5 \\
$30-40$ & 171 & 22.9 \\
$40-50$ & 265 & 35.5 \\
$>50$ & 306 & 41.1 \\
Sex & & \\
Males & 587 & 78.7 \\
Females & 159 & 21.3 \\
Professional Category & & \\
Administrative* & 398 & 53.4 \\
Technicians ** & 181 & 24.3 \\
Drivers and others & 167 & 22.4 \\
\hline
\end{tabular}

* Staff spending most of their time sitting in front of visual display terminals.

** Field operators responsible for technical interventions and maintenance on installations.

\subsection{Prevalence and Profile of Dyslipidemia}

In our study, the prevalence of dyslipidemia were estimated at $60.3 \%$. Pure hypercholesterolemia was the most common (64\%) followed by hypo HDLemia and mixed dyslipidemia of $16.4 \%$ and $12.9 \%$ respectively (Table 2 ).

Table 2. Distribution of workers according to lipid balance disturbances (n $=450$ ).

\begin{tabular}{lll}
\hline & n & \% \\
\hline Number of disturbed parameters & & \\
1 parameter & 205 & 45.6 \\
2 parameters & 171 & 38 \\
3 parameters & 61 & 13.6 \\
4 parameters & 13 & 2.8 \\
Dyslipidemic profile & & \\
Pure hypercholesterolemia & 288 & 64 \\
Mixed hyperlipidemia & 58 & 12.9 \\
Hypo HDLemia & 74 & 16.4 \\
hypertriglyceridemia & 27 & 6 \\
Isolated Hyper LDLemia & 3 & 0.7 \\
Combination of FDRCV* & & \\
0 & 14 & 3.2 \\
1 & 63 & 14 \\
2 & 155 & 34.4 \\
2 and more & 218 & 48.4 \\
\hline
\end{tabular}

Dyslipidemia was isolated in $72 \%$ of cases, combined with another cardiovascular risk factor such as arterial hypertension $(20.2 \%)$, diabetes $(7.1 \%)$ and ischemic heart disease $(1.1 \%)$. 


\subsection{Factors Associated with the Dyslipidemias}

Dyslipidemia was significantly more common among overweight (overweight and obese) subjects, high blood pressure, and among subjects with more than two cumulative risk factors (Table 3).

Table 3. Factors associated with the dyslipidemias.

\begin{tabular}{llll}
\hline & \multicolumn{2}{l}{ Dyslipidemia } & \multirow{2}{*}{ p } \\
\cline { 2 - 3 } & Yes & No & \\
\hline Professional Category & & & \\
Administrative & $253(56,2)$ & $145(49)$ & Ns \\
$\begin{array}{l}\text { Technicians } \\
\text { Drivers and others }\end{array}$ & $99(22)$ & $68(23)$ & \\
Alcohol consumption & $98(21,8)$ & $83(28)$ & \\
yes & & & \multirow{2}{*}{ Ns } \\
No & $125(27,8)$ & $93(31,4)$ & \\
Practice of physical activity & $325(72,2)$ & $203(68,6)$ & \\
Yes & $101(22,4)$ & $53(17,9)$ & \\
No & $349(77,6)$ & $243(82,1)$ & \\
Body mass index & & & \\
$<18$ & $3(0,7)$ & $5(1,7)$ & \\
$18-25$ & $123(27,3)$ & $138(46,6)$ & \\
$25-30$ & $209(46,4)$ & $100(33,8)$ & \\
$>30$ & $115(25,6)$ & $53(17,9)$ & \\
\hline
\end{tabular}

\section{Discussion}

The classification used to define the dyslipidemic profiles in our study, as Ferrieres J notes, is rather caricatural and does not reflect the subtleties of the pathophysiology of dyslipidemias [22]. However, it is a pragmatic approach to better manage the various lipid abnormalities in daily practice. The major role of dyslipidemias as a risk factor in the genesis of cardiovascular disease has been clearly demonstrated in epidemiological surveys of population cohorts around the world [23-26].

The prevalence of the dyslipidemias in our study was $60.3 \%$. This prevalence is well above the data reported by Agoudavi K and Balaka A in Togo and those of Gao Y found in the workplace in China [20-21, 27]. High prevalences have been described in the general population in Africa, thus testifying to the ubiquitous nature of the phenomenon [9-10, $15,28,29-30]$. At the root of this scourge is the nutritional transition that has accompanied the rapid and poorly controlled urbanization of our tropical countries and characterized by the passage of a monotonous diet, rich in starch and fiber, low in fat and a physically active life to a high-calorie diet and a sedentary lifestyle $[5,20]$. The predominance of the hypercholesterolemias in our study is similar to those reported in the workplace by Balaka A et al. in Togo, Mbaye A and al in Senegal and also comparable to the findings of the STEPS Togo 2010 survey [12, 20-21]. The dyslipidemias were significantly associated with the arterial hypertension and with the overweight (overweight and obesity), this last association being frequently reported by some authors in the literature [3032]. This reveals the complexity of cardiovascular pathology where, apart from the traditional risk factors (age, gender and heredity), behavioral factors such as diet, sedentary lifestyle and obesity are intertwined in a vicious circle, on which are grafted professional and psychosocial factors that are emerging in the workplace [33]. Hence the need to put in place, within the framework of decent work advocated by the International Labor Organization (ILO), real prevention programs focusing as much on occupational risks as on cardiovascular diseases with a particular emphasis on promoting a healthy lifestyle, including regular physical activity and a balanced diet [34].

\section{Conclusion}

This work completed in professional environment shown the reality of dyslipidemias where they are dominated by the pure hypercholesterolemias and associated to other factors of risks like high blood pressure, overweight and sedentary lifestyle. This observation should motivate the implementation of prevention programs at national level and relayed in the workplace. These programs should take into account the recommendations of the WHO, with a focus on promoting a healthy and balanced diet and a healthy lifestyle. If the nutritional transition seems to mainly explain the phenomenon in the general population, in professional environment the influence of certain occupational factors such as the psychosocial risks, work in prolonged sitting position were evoked but could not be evaluated because of the descriptive nature of our study. Thorough later studies should be undertaken to seek the occupational factors associated with the dyslipidémies in professional environment. However in margin of that, the implementation of prevention programs at national level and relayed in professional environment proves to be necessary to fight against this plague whose socio-economic consequences are priceless. These programs should take into account the recommendations of WHO; with an accent on the promotion of a healthy and balanced food just as a good hygiene of life.

\section{Conflict of Interest Statement}

The authors declare that they have no competing interests.

\section{References}

[1] P. K. Streatfield, W. A Khan, A. Bhuiya, S. M. A. Hanifi and al. Noncommunicable Disease Mortality in Africa and Asia: Evidence from INDEPTH Health and Demographic Surveillance Systems. Global Health Action, 7, 25365.

[2] P. K. Streatfield, W. A. Khan, A. Bhuiya, N. Alam and al. Cause-specific mortality in Africa and Asia: evidence from INDEPTH health and demographic surveillance system sites. Global Health Action, 7, 25362.

[3] S. B Gning, M. Thiam, F. Fall, K. Ba-Fall, P. S. Mbaye, L. Fourcade. Diabetes mellitus in sub-Saharan Africa, epidemiological aspects, management difficulties. Med Trop 2007; 67: 607-611.

[4] K. Steyn, K. Sliwa, S. Hawken S and al. Risk factors associated with myocardial infarction in Africa: the INTERHEART Africa study. Circulation 2005; 112: 3554-61. 
[5] J. E. Touze. Cardiovascular diseases and the epidemiological transition of the tropical world. Med Trop 2007; 67: 541-542.

[6] WHO. Quantifying selected major risks to health. In: The WHO Report 2002- Reducing risks, promoting healthy life. Chap 4: Geneva: WHO; 2002. p. 47-97.

[7] C. Scheidt-Nave, Y. Du, H. Knopf, A. Schienkiewitz, T. Ziese, E. Nowossadeck, A. Gößwald, MA. Busch. Prevalence of dyslipidemia among adults in Germany: Results of the German Health Interview and Examination Survey for Adults (DEGS 1). BGG. 2012; 56 (5 6): 32530.

[8] YS. Khader, A. Batieha, M. El-Khateeb, M. Al Omari, K. Ajlouni. Prevalence of dyslipidemia and its associated factors among Jordanian adults. J Clin Lipidol. 2010; 4 (1): 53-8.

[9] A. Yahia-Berrouiguet, M. Benyoucef, K. Meguenni, B. Faivre, M. Brouri. Survey on the prevalence of risk factors for cardiovascular diseases in Tlemcen (Algeria). Diabetes Metab. 2009; 35 (1): 42-3.

[10] MS / WHO. Noncommunicable Disease Survey Report according to the WHO STEPwise Approach? Study of arterial hypertension, diabetes and other risk factors in Nouakchott Mauritania. 2006.

[11] F. Cisse, FD, Agne, A. Diatta, AS. Mbengue, A. Ndiaye, A. Samba, S. Thiam, D. Doupa, GN. Sarr, ND. Sall, M. Toure. Prevalence of dyslipidemias at the biochemistry laboratory of Aristide le Dantec University Hospital in Dakar, Senegal. Pan Afr Med J 2016; 25: 67.

[12] A. Mbaye, M. B. Ndiaye, A. D. Kane, F. Ndoume, S. Diop, N. V. Yameogo, A. Kane. Occupational medicine around the world. Screening for cardiovascular risk factors among workers of a private telecommunications company in Senegal. Arch Mal Prof 2011; 72: 96-99.

[13] G. Tiahou, K. Deret, A. World, M. Agniwo Camara-Cisse, Y. Djohan, P. Djessou, D. SESS. Frequency of lipid balances and prevalence of dyslipidemias in the biochemistry laboratory of the Cocody chu. J Sci Pharm Biol. 2010; 11 (2): 60-5.

[14] FB. Micah, BC. Nkum. Lipid disorders in hospital waiting in Kumasi, Ghana. Ghana Medical Journal. 2012; 46 (1): 14-21.

[15] Oguejiofor OC, Onwukwe CH, Odenigbo CU. Dyslipidemia in Nigeria: prevalence and pattern. Ann Afr Med. 2012; 11 (4): 197202.

[16] F. Damorou, E. Togbossi, S. Pessinaba, Y. Klouvi, A. Balogou, M. Belo, B. Soussou. Strokes and Cardiovascular Emboligens. Mali Medical 2008; 23 (1): 31-33.

[17] F. Damorou, E. Togbossi, S. Pessinaba, B. Soussou. Epidemiology and circumstances of discovery of high blood pressure hypertension in hospitals in Kpalimé (secondary city of Togo). Mali Medical 2008; 23 (4): 17-20.

[18] Republic of Togo. Inter-Ministerial Order No. 004/2011/ MTESS / MS establishing a safety and health service at work, in accordance with Articles 175 and 178 of the Labor Code.

[19] C. Andryszak, E. Morel. Relevance of the exploration of lipid abnormalities by an occupational health service. doi: Arch. Wrong. Teacher. Approx. 10.1016/ j.admp.2012.03.141.

[20] K. Agoudavi and al. Final report of STEPS Togo 2010 survey. Ministry of Health, Togo 2012.

[21] A. Balaka, MA. Djibril, T. Tchamdja, KA. Djagadou, E.
Mossi, KD. Nemi. Ischemic heart disease and dyslipidemia in a postal professional environment in Togo. RAFMI 2017; 4 (1-2): 7-9.

[22] J. Ferrieres, JB. Ruidavets, B. Perret, J. Dallongeville, D. Arveiler, A. Bingham, P. Amouyel, B. Haas. Prevalence of dyslipidemias in a representative sample of the French population. Heart and Vessel Archives 2005; 98 (2): 127-132.

[23] KM. Anderson, WP. Castelli, D. Levy. Cholesterol and Mortality: 30 years of follow-up from the Framingham study. JAMA. 1987; 257 (16): 2176-80.

[24] G. Assmann, P. Cullen, H. Schulte. The Munster Heart Study (PROCAM): Results of follow-up at 8 years. Eur Heart J. 1998; 19 (substitute A): A2-A11.

[25] C. Peretti, C. Perel, F. Chin, P. Tuppin, MC. Iliou, M. Vernay, and al. Average LDL cholesterol and the prevalence of LDL hypercholesterolemia in adults aged 18 to 74 , National Nutrition and Health Study (ENHS) 2006-2007, Metropolitan France. BEH 2013; (31): 378-85.

[26] A. Aouba, M. Eb, G. Rey, G. Pavillon, E. Jougla. Data on mortality in France: main causes of death in 2008 and developments since 2000. BEH.

[27] Y. Gao, XN. Zhong, YH. Yang, KC. Tian. Plasma lipid level and incidence of dyslipidemia in workers of Chongqing enterprises and institutions. Zhonghua xin xue Guan Bing za zhi 2012; 40 (5): 432-435.

[28] L. P Thiombiano, A. Mbaye, S. A. Sarr, A. A. Ngaide, Ab. Kane, M. Diao, Ad. Kane, S. A. Ba. Prévalence de la dyslipidémie dans la population rurale de Guéoul (Sénégal). Annales de Cardiologie et d'Angéiologie 2016; 65 (2): 77-80.

[29] D. Doupa, A. S. Mbengue, F. A. Diallo, M. Jobe, A. Ndiaye, A. Kane, A. Diatta, M. Touré. Lipid profile frequency and the prevalence of dyslipidemia from biochemical tests at Saint Louis University Hospital in Senegal. Pan African Medical Journal 2014; 17: 75.

[30] N. Mezghanni, M. Mnif, A. Lahiani, A. Lassouad, M. Kamoun, K. Jamoussi, F. Ayadi, H. Mejdoub, M. Abid. Effet du mode de vie active ou sédentaire sur le profil lipidique chez la femme obèse. Diabetes \& Metabolism 2011; volume 37 (1): A37-38. Disponible: http://www.diabet metabolism.com/article/S1262363611706358/fulltext.

[31] E. Asma, H. M. Dhouha, M. Anwar, N. Fadoua, D. Wahiba, G. Lotfi，F. N. Mohamed. Obésité et dyslipidémie chez des patients bipolaires tunisiens. Annales de Biologie Clinique 2011; 68 (3): 277-84.

[32] C. Erem, A. Hacihasanoglu, O. Deger, M. Kocak, M. Topbas. Prevalence of dyslipidemias and associated risk factors among Turkish adults: Trabzon Lipid Study. Endocrine. 2008; 34 (13): $36-51$.

[33] S. L. Sauter, Jr J. J. Hurrel, L. R. Murphy, L. Levi. Les facteurs psychosociaux et organisationnels. In: Encyclopédie de la sécurité et de la santé au travail. Genève: Bureau International du Travail, 3è édition française, vol II, 2000, 34. 2.

[34] K. Rouffiac, G. Boudet, P. Bailly, I. Biat, F. Dutheil, A. Chamoux. Détection des sujets à haut risque cardiovasculaire: bilan de sept années de dépistage actif et stratégie d'action en milieu de travail. Arch. Mal. Prof. Env 2012; 73: 339-343. 